\title{
Culture Variation in Ingroup Bias: Exposure to Individualist Culture's Influence on People from Collectivist Culture
}

\begin{abstract}
Yuexin Zou
Guangzhou Zhixin High School, Guangzhou, 510260, China, 1684696790@qq.com

ABSTRACT

The psychological mechanisms that underlie cultural variation in ingroup bias between collectivist and individualist cultures is a highly discussed topic. Evidence from past research suggests that ingroup bias and collectivismindividualism are closely related. This study will further investigate this relationship by focusing on students deciding whether or not to study abroad. I will discuss whether or not the intention of students from collectivist cultures to study aboard is concerned with exposure to individualism, as well as whether the latter is related to their ingroup bias. I will further investigate the change of students' level of ingroup bias after one year of study to see whether exposure to individualist culture influences people from collectivist culture.
\end{abstract}

Keywords: ingroup bias, culture variation, individualist culture and collectivist culture.

\section{INTRODUCTION}

\subsection{Background}

Ingroup bias, namely, the tendency to prefer the group to which one belongs has been one of the most wellsupported psychological findings. It is the positive evaluation of the ingroup, a group of people to which one identifies or finds belonging, in contrast to the outgroup, a group of people which one does not identify[1]. In real life, people tend to favor their ingroup because of competition, self-interest or group boundaries, etc. For example, during a competition of team leaders, people are more likely to vote for their family members compared other than to someone else that has no relationship to their family. However, the research by Tajfel et al [2]demonstrated that ingroup bias can occur when group boundaries are meaningless and self-interest is not involved.

Researchers found that, even without meeting other group members, participants who are categorized into two separate groups via some random processes or based on relatively trivial criteria still tend to exhibit in-group favoritism and out-group derogation [1][2]. The measurement called "minimal group" paradigm is designed to test this psychological phenomenon known as the minimal group effect (MGE). This paradigm required that (a) individuals have no face-to-face contact, (b) group membership is completely anonymous, (c) there is no instrumental or rational link between the categorization and the experimental tasks to be completed by participants, and (d) the responses by participants have real implications for the groups, but not the responding individual [2]. It was repeatedly found that ingroup preference emerged even when individuals were placed into previously unknown and arbitrary social groups, such as the ones based on preference in colors, numbers, or even random assignment [1][2][3]. These findings and the subsequent repetitive findings have been taken as evidence that ingroup favoritism is a psychological phenomenon that arises from robust internal factors rather than external factors such as real conflict or competition.

However, this does not mean that other social factors cannot influence the extent of ingroup bias, thus researchers have conducted experiments to see the influence of social effects. Many researchers have noted cultural differences [4][5] and discussed whether social identity processes are more or less significant in collectivist compared to individualistic societies. The individualism-collectivism cultural syndrome [6] appears to be the most significant cultural difference among cultures. In collectivist cultures, people are 
interdependent within their in-groups (family, nation, etc.), give priority to the goals of their in-groups, shape their behavior primarily on the basis of in-group norms, and behave in a communal way. In individualist societies, people are self-reliant, autonomous and independent from their in-groups. They give priority to their personal goals over the goals of their in-groups, they behave primarily on the basis of their attitudes, beliefs, and convictions rather than the norms of their in-groups, and exchange theory adequately predicts their social behavior. Individualism is more typical of Western Europe and North American societies, whereas collectivism is a typical socialization pattern in much of Asia, Africa, Eastern and Southern Europe, and South America. Connection between individualism-collectivism and ingroup bias has been a hotspot research topic in many years. Many researchers reported that collectivism might be associated with higher levels of ingroup bias[7][8]. Notably, Wang and his colleagues [9] found that Chinese participants view social groups as more entitative than Americans and, as a result, are more likely to infer personality traits on the basis of group membership, thereby having higher levels of ingroup bias.

On account of a multitude of research indicating individualism-collectivism and ingroup bias is closely related, the present study thus aims to further investigate this relationship. However, what has not been addressed previously is whether exposure to a second culture can have an effect on people's ingroup bias. Thus, the present study aims to investigate whether a second exposure to a different culture (individualist culture for people who originated in collectivist culture) can affect people's level of ingroup bias. As we know, living in another country is one of the most significant ways you can be exposed to another culture. Thus, I want to investigate the difference in ingroup bias between students who have studied abroad versus those who have not.

\subsection{The current study}

The present study is led by three aims of researching the topic of cultural variation in ingroup bias. Students who intend to study abroad are likely to have come to this decision due to exposure to that culture. It is possible that students from collectivist countries who intend to study in individualist countries have been guided to do so through exposure to western culture through social media or elective classes at school. If individualism is related to lower ingroup bias, then exposure to individualism might lower a collectivist individual's level of ingroup bias. Therefore, my second aim is to investigate whether students' intentions to study abroad in individualist cultures correlates with their levels of ingroup bias. Finally, living in another culture represents the highest possible exposure to that culture. Thus, my finally aim is to investigate whether living in an individualistic culture significantly reduces the level of ingroup bias of students previously living in collectivist cultures.

\section{HYPOTHESIS}

Hypothesis 1: Students' intentions to study abroad (in individualist countries) will positively correlate with their exposure to individualist cultures.

Most students who intend to study abroad are probably attracted by the culture or environment there for they have seen descriptions of it or learned the histories and cultures from class or foreign friends. Thus, it is very likely that students who intend to study abroad have higher exposure to individualist cultures.

Hypothesis 2: Students' intentions to study abroad (in individualist countries) will negatively correlate with their levels of ingroup bias.

If hypothesis 1 holds true that students who intend to study abroad often have a bigger tendency to be exposed to individualist cultures from social media or related social activities, it is likely that they have higher levels of ingroup bias. Thus, it is necessary to test this second hypothesis to see if exposure to individualist culture is related to people's level of ingroup bias.

Hypothesis 3: After 1 year of study, students who studied abroad (in individualist countries) will show a significant decrease in ingroup bias in comparison to those who did not study abroad.

Students who have the experience of studying in an individualist country for one year are most likely to have more exposure to individualist cultures, and if people from collectivist cultures tend to have a higher level of ingroup bias, these students would have a significant decrease in ingroup bias. Since most research states that collectivism is positively related to ingroup bias, I believe there is a causal relationship between exposure to individualist cultures and students' ingroup bias.

\section{METHOD}

\subsection{Participant}

To reduce the influence of confounding variables, I chose 20 or 21 years old Chinese Junior year University students from Peking University deciding whether or not to study a year abroad or take part in an exchange program in Individualist countries to be the participants. The participants all have the ethnicity of China and consider Chinese as their ingroup in the first place.

\subsection{Procedure}

The participants will first be required to fill in a selfreport questionnaire that asks them about some descriptive information and their tendency of studying abroad in an individualist country. Before one year of 
study, they need to go through some measurements to test their level of ingroup bias and their exposure to individualist cultures at that time. After one year of study, the participants are asked to test their exposure to individualist cultures to avoid significant individual differences in each of the two groups. Afterwards, they will test their level of ingroup bias again. Upon completion of the tests, they will be debriefed and thanked.

\subsection{Measures}

\subsubsection{The intention of studying abroad.}

In this work, we use a self-report questionnaire as the major measurement of their intention of studying abroad. This questionnaire includes 10 items. The major question in this questionnaire which asks the participants directly about their extent of intending to study abroad requires a response on a 7 -point rating scale in which $1=$ Never intended to study abroad, $2=$ having a mere intention that might not be realistic, $3=$ with some intention to study abroad, 4=with an actual intention to study abroad, $5=$ with a relatively high intention of studying abroad, $6=$ Keenly intend to study abroad, and 7=with an absolute intention to study abroad. The other 9 questions are yes or no questions that asks participants about their motivation behind their intention. For example, "If you do not intend to study abroad, are your intentions economically motivated?" These questions are designed to learn what are the possible reasons that participants' intention of studying abroad is not positively related to their exposure to ingroup bias.

\subsubsection{Exposure to individualist culture.}

Exposure to western culture (EWCS)[10]is a selfreport measure that assesses the individual levels of exposure to western culture. The questionnaire was developed to assess western influences in an individual's life, including social, familial, educational, vocational, interpersonal, and recreational aspects among others. The measure also includes questions related to the influence of western culture on food, entertainment, attire, means of communication, resources of knowledge and information, technology, marriage, and living arrangements. The present study would build a 1-7 scale based on this EWCS questionnaire to evaluate the extent of exposure to individualist culture according to this scale. To test the first hypothesis of whether exposure to individualist culture is related to participants' intention of studying abroad, I will build a scale of one to seven according to participants' answers to the 83 specially designed questions to calculate the extent of participants' exposure to individualist culture. This measure will also be used to test if there are high individual differences in each of the two groups. If some participants who studied abroad in an individualist culture turn out to have extremely low exposure to individualist culture or participants who studied at home in China have extremely high exposure to individualist culture, their data will not count. When it comes to the test of the third hypothesis, I will divide the participants into two groups. One is group for participants who have studied abroad in an individualist country for a year and the other one is the participants who studied at home in China. The group with participants who study abroad is considered to have a higher exposure to individualist culture.

\subsubsection{Ingroup bias}

Two measurements will be used to measure the participants' level of ingroup bias: Implicit Association test for implicit bias and Self-report questionnaire for explicit bias. Implicit Association Test [11] provides a measure of the extent of people's automatic associations. The IAT test used in the current study is similar to the IAT test of race. The ingroup is set as Chinese and the outgroup would be a mix of different ethnicities. The speed at which the participant associates the target with the trait is measured to calculate the level of ingroup bias. Two scores will be measured as the outcome of the test. One is the ingroup favoritism, which is measured as the difference in response time between ingroup faces and outgroup faces alongside positive trait words. The other one is outgroup derogation which is calculated as the difference in response time between ingroup faces and outgroup faces alongside negative trait words. The two scores will be combined to represent the participants' level of implicit bias.

A self-report questionnaire which has a scale of seven different levels of ingroup bias is used to test participant's explicit bias. This questionnaire is comprised of 4 questions that ask them about their extent of preference, identification, attachment, and willingness to help Chinese group and the mix of different ethnicities group. Each question is designed on a scale of one to seven in which the first one is having a strong tendency to Chinese and the last one is having a strong tendency to mix of different ethnicities.

\section{PREDICTED RESULT}

\section{Study 1}

The predicted result for the relationship between intention to study abroad and exposure to individualist culture is closely positively correlated. The correlation coefficient which represents the relationship between the measured result of participants' exposure to individualist cultures from the EWCS questionnaire and participants' answers to their extent of intention to study abroad are evaluated to test the first hypothesis. The possible result would range between 0.65 and 0.99 , and the p-value would be below 0.05 . The predicted result shows that 
intention to study abroad and their exposure to individualist cultures is positively related.

The alternative result would be the value of $r$ ranging between -0.20 and 0.20 which indicates that the exposure and intention are loosely related. This is possibly led by other reasons that may affect students' intention to study abroad like economic reasons. This result indicates that exposure to individualist culture is not the main reason why people chose to study abroad or chose to study at home for collectivist individuals.

\section{Study 2}

We make prediction that extend of exposure to individualist culture and ingroup bias is negatively correlated. The result of participants' EWSC level which was calcuted in a scale of one to seven and their level of ingroup bias (calculated with both the score of implicit bias and the score of explicit bias) will be calculated to see if there is a distinct relationship between Individualism-Collectivism and people's level of ingroup bias. The predicted r-value is about -0.60 to -0.95 with the $\mathrm{p}$-value below 0.05 . This result indicates that exposure to individualist culture for people who originated from a collectivist culture is negatively related to their levels of ingroup bias. This provides an answer to the second hypothesis.

The alternative result would be the r-value lying between -0.20 and 0.20 . This is a possible alternative result since a lot of researchers have pointed out that the relationship between individualism-collectivism and ingroup bias is only distinct under certain conditions[5]. This result indicates that the exposure is not closely related to participants' ingroup bias, thus ingroup bias and individualism-collectivism are not correlated.

\section{Study 3}

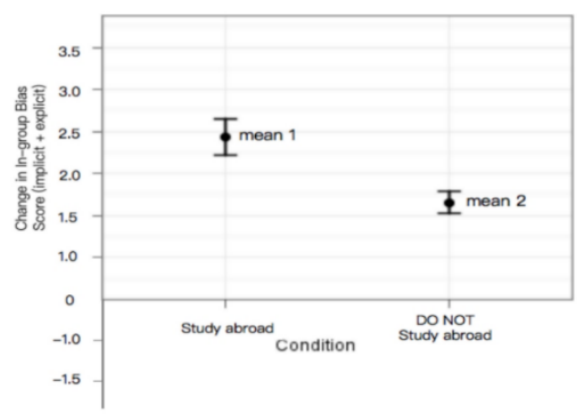

Figure1: change in ingroup bias between group that studied abroad and the group that did not.

The predicted result of the examination of the third hypothesis is that there were distinct difference and the group who studied abroad would appear to have a more significant raise in levels of ingroup bias. The two groups' changes in their levels of ingroup bias are calculated by subtracting their ingroup bias score before and after one year of study. The mean value of the two groups' scores of their change in ingroup bias is compared by conducting a t-test. The predicted p-value is less than 0.05 , as shown in the graph, thus there is a significant difference. The students who studied board in individualist countries have a distinctive decrease in ingroup bias compared to those who studied at home in China.

The alternative result would be the p-value $>0.05$ which indicates that there is not a causal relationship between exposure to individualist cultures and levels of ingroup bias. This result may be obtained if the result of our first study gets the result of a mere relationship between individualism-collectivism and ingroup bias or the phenomenon that an increase in ingroup bias is positively related to exposure to individualist culture.

\section{CONCLUSION}

The result of the study provides evidence of the relationship between ingroup bias and exposure to individualist culture for collectivist people. The participants display a strong relationship between their intention to study abroad and exposure to individualist culture as well as the relationship between exposure to individualist culture and their levels of ingroup bias. This all suggests that exposure to individualist culture is negatively related to ingroup bias, which is consistent with previous studies[9]. The change in ingroup bias also suggests that there is a causal relationship between studying abroad in individualist countries and a decline in ingroup bias.

Certainly, there are many limitations in this design of research. In the present study, I assumed that the change occuring in participants' first year of study mainly depends on whether or not they are studying in an individualist country. However, there are other possible influences, such as studying in a foreign country of collectivist culture, that are supposed to be considered as confounding variables. Moreover, collecting data only from one university might provide the studied with biased data, thus, for further study, it is better to collect data from more universities.

\section{REFERENCES}

[1]. Brewer, M. B. (1979). In-group bias in the minimal intergroup situation: A cognitive-motivational analysis. Psychological bulletin, 86(2), 307.

[2]. Tajfel, H., Billig, M. G., Bundy, R. P., \& Flament, C. (1971). Social categorization and intergroup behaviour. European journal of social psychology, 1(2), 149-178.

[3]. Mullen, B., Brown, R., \& Smith, C. (1992). Ingroup bias as a function of salience, relevance, and status: An integration. European journal of social psychology, 22(2), 103-122. 
[4]. Yamagishi, T., Jin, N., \& Miller, A. S. (1998). Ingroup bias and culture of collectivism. Asian Journal of Social Psychology, 1(3), 315-328.

[5]. Fischer, R., \& Derham, C. (2016). Is in-group bias culture-dependent? A meta-analysis across 18 societies. SpringerPlus, 5(1), 1-9.

[6]. Triandis, H. C. (1996). The psychological measurement of cultural syndromes. American psychologist, 51(4), 407.

[7]. Hinkle, S., \& Brown, R. (1990). Intergroup comparisons and social identity: Some links and lacunae. Social identity theory: Constructive and critical advances, 48, 70 .

[8]. Hogg, M. A. (2007). Uncertainty-identity theory. Advances in experimental social psychology, 39, 69-126.

[9]. Spencer-Rodgers, J., Williams, M. J., Hamilton, D. L., Peng, K., \& Wang, L. (2007). Culture and group perception: Dispositional and stereotypic inferences about novel and national groups. Journal of personality and social psychology, 93(4), 525.

[10].Ram, S. I. (2010). Exposure to western culture in relation to individualism, collectivism and subjective well-being, in India. Illinois Institute of Technology.

[11]. Greenwald, A. G., McGhee, D. E., \& Schwartz, J. L. (1998). Measuring individual differences in implicit cognition: the implicit association test. Journal of personality and social psychology, 74(6), 1464. 